\title{
$N\left({ }^{2} D,{ }^{2}\right.$ P) METASTABLE ATOMS PRODUCTION IN A N 2 D.C. GLOW DISCHARGE.
}

\author{
G. Cernogora, G. Gousset, A. Ricard.
}

Laboratoire de Physique des Gaz et des Plasmas, Bat. 212, Université Paris Sud 91405 Orsay, France.

\section{1) Introduction}

The $\mathbb{N}\left({ }^{2}{ }^{2}{ }^{2} \mathrm{P}\right)$ metastable species are of a peculiar interest in the plasma chemistry processes with nitrogen, for example the reaction: $\mathrm{N}\left({ }^{2} \mathrm{D}-{ }^{2} \mathrm{P}\right)+\mathrm{O}_{2} \rightarrow \mathrm{NO}+0$. Concentrations of $\mathrm{N}\left({ }^{2} \mathrm{D}-{ }^{2} \mathrm{P}\right)$ have been previously measured by LinKaufman [1] in microwave discharges in order to study the quenching reactions $\mathrm{N}\left({ }^{2} \mathrm{D}-{ }^{2} \mathrm{P}\right)+$ molecules. The overall production rates of these atomic metastable species by electrons collisions are not known at the present time. Only some cross sections for the excitation of NI spectral lines are known. In the present study we plan to determine the excitation rates of $\mathrm{N}\left({ }^{2} \mathrm{Dr}{ }^{2} \mathrm{P}\right)$ by electron collin sions in a $\mathrm{N}_{2}$ glow discharge.

2) Experimental results

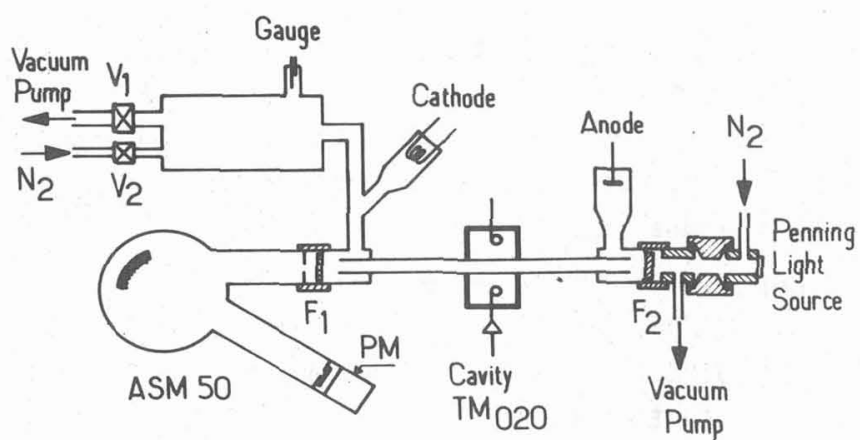

$\mathrm{F}_{1} . \mathrm{F}_{2}: \mathrm{MgF}_{2}$ Windows.

$V_{1} \cdot V_{2}$ : Valves.

PM : Photomultiplier.

\section{Fig. 1}

The experimental arrangement is shown in fig. 1. A N 2 d-c glow discharge is produced in a $2 \mathrm{~cm}$ diameter, $50 \mathrm{~cm}$ long pyrex tube. Pressure is varying from 0.5 to 1.5 Torr and discharge current from 1 to $50 \mathrm{~mA}$. The $\mathrm{N}\left({ }^{2} \mathrm{D}-{ }^{2} \mathrm{P}\right)$ concentrations are measured by optical absorption. The optical source is a Penning discharge in nitrogen emitting strongly the NI spectral lines. The spectral lines are analysed by means of an U.V. (Jobin-Yvon ASM 50) spectrometer with a resolution limit $\delta h=1.3 \AA$.
The spectral lines NI $\quad=1492.6 \AA$ and

$\lambda=1742.7 \AA$ have been chosen to determine the $\mathbb{N}\left({ }^{2} \mathrm{D}\right)$ and $N\left({ }^{2} \mathrm{P}\right)$ concentrations. The Mitchell Zemanski [2] method has been used, the coefficient $\alpha=\frac{\text { incident line broadening }}{\text { absorption line broadening }}$ has been determined in calculating the Doppler and natural broadenings in the source and the absorption tube. Temperatures are evaluated from the rotational structure of the second positive $\mathrm{N}_{2}$ band,

$\lambda=3371 \AA$. We have found a mean temperature of $500^{\circ} \mathrm{K}$. Calculating the metastable concentrations from the absorption measurements we have taken into account the fine structure of NI lines and the instrumental hroadening $[3]$ (dissymetrical profile with $\delta \lambda_{1 / 2}=1.3 \AA$ ). The results for an absorption length $\mathrm{L}=50 \mathrm{~cm}$ and a temperature $\mathrm{T}=500^{\circ} \mathrm{K}$ are shown in fig. 2 .

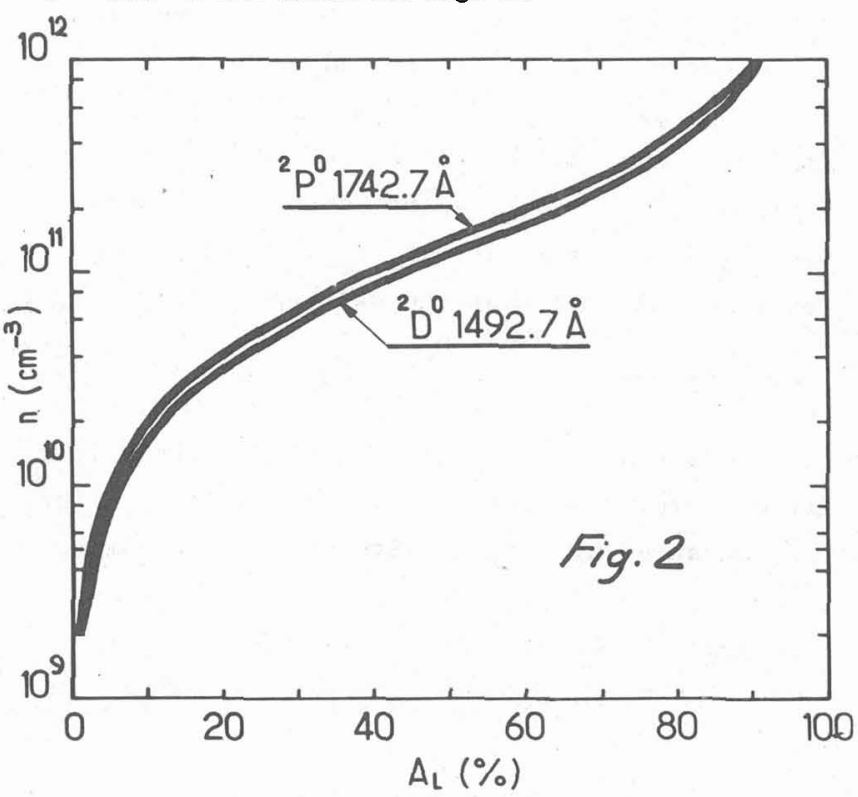

Concentrations of $N\left(C^{2} D, 2\right)$ metastable have been determined as functions of the discharge current for a given $\mathrm{N}_{2}$ pressure. For $\mathrm{I}<10 \mathrm{~m} \mathrm{~A}$, densities increase linearly with current.

In the range $] 0<1<50 \mathrm{~mA}$ the metastable concentrations are nearly saturated. 
At 0.7 Torr, I $=50 \mathrm{~m} \mathrm{~A}$, the saturated values are n $\left({ }^{2} \mathrm{D}\right)=7( \pm 1.5) \times 10^{10} \mathrm{~cm}^{-3}$

$n\left({ }^{2} \mathrm{P}\right)=12.5( \pm 2.5) \times 10^{10} \mathrm{~cm}^{-3}$

3) Discussion

In stationary conditions, variations of metastable concentrations are given by :

$$
n_{M}=\frac{n_{0} n_{e} c_{e}^{M}}{D_{m} / \Lambda^{2}+n_{0} c_{M}^{0}+n_{e} c_{M}^{e}}
$$

where :

$-n_{M}, n_{Q}, n_{e}$ are the concentrations of $N\left(2_{D}-{ }^{2}\right)$ metastables, $N_{2}$ neutrals and electrons. $-C_{e}^{M}$ is the excitation rate by electrons $\left(\mathrm{C}_{\mathrm{e}}^{\mathrm{M}}=\left\langle\sigma_{\mathrm{e}}^{\mathrm{M}} \mathrm{w}_{\mathrm{e}}\right\rangle, \sigma_{\mathrm{e}}^{\mathrm{M}}\right.$ excitation cross section and we electrons velocity) $C_{M}^{e}$ and $C_{M}^{o}$ are the destruction rates by electrons and $\mathrm{N}_{2}$ molecules - $D_{M} \wedge^{2}$ is the frequency of metastables diffusion and destruction on the tube wall, $\Lambda=\frac{R}{2.4}$ for a Bessel fundamental diffusion mode ( $R$ tube radius). The electron concentrations have been measured using a resonant cavity (TM 020 mode). In the present case, the shift of the resonant frequency $\Delta f$ (with and without plasma) is related to the electron density by the numerical relation :

$$
\mathrm{n}_{\mathrm{e}}\left(\mathrm{cm}^{-3}\right)=7 \times 10^{8} \Delta \rho\left(\mathrm{M} \mathrm{H}_{\mathrm{z}}\right)
$$

For $I<20 \mathrm{~mA}$ and $\mathrm{p}<1$ Torr, we have found that the electron density is linearly dependant of the current $:$ ne $=$ bI. Since metastables are also linearly dependent of the current for $I<10 \mathrm{~mA}: \mathrm{n}_{\mathrm{n}}=\mathrm{a} I$, we can deduce that the de-excitation by electrons $\left(n_{e} C_{M}^{e}\right.$ ) can be neglected in eq. 1, and that the creation is given by :

$$
\mathrm{c}_{\mathrm{e}}^{\dot{M}}=\frac{\mathrm{a}}{\mathrm{b} \mathrm{n}_{0}}\left[\frac{\mathrm{D}_{M}}{\Lambda^{2}}+\mathfrak{n}_{0} c_{M}^{\circ}\right]
$$

The diffusion coefficients $D_{M}$ are not given in the lit terature. Only $D\left(N, N_{2}\right)=220 \mathrm{~cm}^{2} \mathrm{sec}^{-1}$ has been measured by Morgan - Schiff [4]. Comparing the data in $\mathrm{Ar}-\mathrm{O}_{2}$ mixtures [1]:

$\mathrm{D}(\mathrm{O}, \mathrm{Ar})=209 \mathrm{~cm}^{2} \mathrm{sec}^{-1}$ and

$D\left(0_{M}, A r\right)=257 \mathrm{~cm}^{2} \mathrm{sec}^{-1}$, we have choosen

$D\left(\mathrm{~N}_{\mathrm{M}}, \mathrm{N}_{2}\right)=250 \mathrm{~cm}^{2} \mathrm{sec}^{-1}$.

Concerning the neutrals destruction coefficient $C_{M}^{0}$, we have used the data published by slanger Black $[5]$ for $N\left({ }^{2} D\right)$ and Lee et $A 1 .[6]$ for $N\left({ }^{2} P\right)$ and found that $C_{2 p}^{\circ}$ can be neglected.

From measurements of $a$ and $b$, we have determined the order of magnitude of
$\mathrm{C}_{\mathrm{e}}^{\mathrm{M}}\left({ }^{2} \mathrm{P},{ }^{2} \mathrm{D}\right): 10^{-10} \mathrm{~cm}^{3} \mathrm{sec}^{-1}$. This value can be compared with previous argon metastable results[7] $\mathrm{C}_{\mathrm{e}}\left({ }^{3} \mathrm{P}_{2}\right)=2( \pm 0.7) \times 10^{-1]} \mathrm{cm}^{3} \mathrm{sec}^{-1}$ for $n_{0} R=10^{16} \mathrm{~cm}^{-2}(R=1 \mathrm{~cm})$. In similar gl ow discharges and for analogous excitation thresholds, the electron production rates experimentaly found for $N\left({ }^{2} D,{ }^{2} P\right)$ are stronger than for $A x\left({ }^{3} P_{2}\right)$. This result can be interpreted as stepwise processes in the production of $\mathrm{N}\left({ }^{2} \mathrm{D},{ }^{2} \mathrm{P}\right)$ by means of the metastable molecular levels $\left.N_{2}\left(A^{3} \Sigma_{*}^{+}\right)^{a} \Pi_{g}\right)$. The argon metastable level is created by a less efficient one $s$ tep process.

\section{4) Concluding remarks}

$\mathrm{N}\left({ }^{2} \mathrm{D},{ }^{2} \mathrm{P}\right)$ concentrations have been determined by optical absorption in a $\mathrm{N}_{2} \mathrm{~d}-\mathrm{c}$ glow discharge $(R=1 \mathrm{~cm})$ at pressures $0,5-1.5$ Torr and discharge currents ] - $50 \mathrm{~mA}$. The electron excitation rates are of the same order of magnitude for

$N\left({ }^{2} \mathrm{D}\right)$ and $N\left({ }^{2} \mathrm{P}\right): \mathrm{C}_{\mathrm{e}}^{\mathrm{M}}\left({ }^{2} \mathrm{P},{ }^{2} \mathrm{D}\right)=10^{-10} \mathrm{~cm}^{3} \mathrm{sec}^{-1}$.

\section{References}

[1] C.L. Lin, F. Kaufman, J. Chem. Phys. 55 (1971) 3760

[2] A.G.G. Mitche11, M.W. Zemanski Resonance radiation and Excited atoms (Cambex Un. Press NY 1961)

[3] G. CERNOGORA - G. GOUSSET - M. POUEY Sème V.U.V. Confërence III (1971) 51

[4] J.E. Morgan, H.I. Schiff, Can.J. Chem. 42 (1964) 2300

[5] T.G. Slanger, G. Black, J. Chem Phys. 64 (1976) 4442

[6] J.H. Lee et a1., J. Chem Phys. 69 (1978) 3069

[7] J.L. Delcroix, C.M. Ferreira, A. Ricard, Principles of Laser Plasmas, Chap. 5 Metas table Atoms and Molecules in Ionized Gases, Ed. G. Bekefi (J. Wiley 1976). 